\title{
Procesos de arraigo y pervivencia de la agricultura algodonera familiar Chaqueña en el Norte Argentino. Aportes para el diseño de políticas públicas con equidad social y sostenibilidad ambiental
}

Rooting and survival processes of Chaqueña family cotton agriculture in the Argentine North. Contributions for the design of public policies with social equity and environmental sustainability

\section{Processos de enraizamento e sobrevivência da agricultura de algodão família Chaqueña no norte argentino. Contribuições para o projeto de políticas públicas com equidade social e sustentabilidade ambiental}

Processus d'enracinement et de survie de l'agriculture cotonnière familiale de Chaqueña dans le nord de l'Argentine. Contributions pour la conception de politiques publiques avec équité sociale et durabilité environnementale

\author{
Cristina Ofelia Valenzuela ${ }^{1}$
}

Recebido em 14/02/2018; revisado e aprovado em 22/02/2018; aceito em 25/03/2018

DOI: http://dx.doi.org/10.20435/inter.v19i4.1842

\begin{abstract}
Resumen: Esta investigación enfoca el proceso de construcción de una territorialidad productiva - la agricultura algodonera familiar - con el apoyo y el sostén de la política pública y sus experiencias de pervivencia en contextos de fuerte reestructuración, postulando que la valoración de estos procesos constituye un insumo primordial para el diseño de estrategias de desarrollo rural.
\end{abstract}

Palabras clave: procesos territoriales; agricultura familiar; algodón.

Abstract: This research focuses on the process of construction of a productive territoriality - family cotton agriculture - with the support and support of public policy and its experiences of survival in contexts of strong restructuring, postulating that the evaluation of these processes constitutes an essential input for the design of rural development strategies.

Key words: territorial processes; family farming; cotton.

Resumo: Esta pesquisa centra-se no processo de construção de uma territorialidade produtiva - agricultura de algodão familiar - com o apoio e apoio das políticas públicas e suas experiências de sobrevivência em contextos de forte reestruturação, postulando que a avaliação desses processos constitui um insumo essencial para o desenho de estratégias de desenvolvimento rural.

Palavras chave: processos territoriais; agricultura familiar; algodão.

Résumé: Cette recherche se concentre sur le processus de construction d'une territorialité productive l'agriculture familiale du coton - avec le soutien et le soutien des politiques publiques et de ses expériences de survie dans des contextes de forte restructuration, postulant que l'évaluation de ces processus constitue un apport essentiel. la conception de stratégies de développement rural.

Mots-clés: processus territoriau, agriculture familiale, coton.

\section{INTRODUCCION}

El área de estudio se sitúa en la provincia del Chaco, espacio que se fue organizando a lo largo del siglo XX con un fuerte componente identitario asociado al algodón a escala familiar (en explotaciones de menos de 100 hectáreas). En este escenario, las transformaciones ocurridas en los últimos 20 años involucraron procesos de redistribución de los recursos y de las oportunidades

\footnotetext{
${ }^{1}$ Instituto de Investigaciones Geohistoricas, Chaco, Argentina.
} 
entre los actores tradicionales que sustentaban una territorialidad algodonera de tipo familiar y los nuevos agricultores, con manejos altamente tecnificados, costosos y totalmente desvinculados de los espacios de aplicación. La presión expansiva de las nuevas modalidades de usufructo del espacio productivo, dio lugar a un profundo proceso de reestructuración de la agricultura Chaqueña, calificado por Aparicio (2005, p. 210) como "el más dramático de la agricultura argentina".

Por su parte la pervivencia del sector de pequeños y medianos agricultores, protagonistas de la agricultura familiar tradicional, con una trayectoria de décadas de producción en el ámbito Chaqueño se mantuvo hasta la actualidad (2017), por medio de ciertos hábitos, costumbres y prácticas que les fueron posibilitando su subsistencia cotidiana en un contexto de reestructuración productiva que no facilitaba su inclusión como agentes económicamente viables.

En este artículo se examina tanto el proceso de construcción de una territorialidad productiva - la agricultura algodonera familiar - con el apoyo y el sostén de la política pública, como sus experiencias de pervivencia en contextos de fuerte reestructuración productiva.

\section{INSTRUMENTOS CONCEPTUALES DE BASE, METODOLOGÍA DE ESTUDIO Y PLANTEO DEL PROBLEMA}

El concepto de territorio admite una multiplicidad de lecturas e interpretaciones, con base por una parte en los elementos y factores seleccionados para decodificarlo y por otra en las perspectivas teóricas y disciplinares que guían el análisis. En este sentido, y partiendo de la premisa de explicar la importancia del algodón en la construcción territorial del Chaco agrícola es posible afirmar que aquel constituyó la base de la organización del interior Chaqueño desde las primeras décadas del siglo XX, acompañando el arraigo de los colonos en ese ámbito. Esta trascendencia como factor de anclaje, recurso económico y elemento de identificación socioproductiva para miles de familias rurales fue una constante en el examen del desarrollo territorial chaqueño en los últimos 80 años.

La permanencia de esa orientación productiva permite asociarla al proceso de construcción de una "cultura de tipo territorial", entendida por Palacio et al. (2014, p. 93) como aquella estrechamente ligada a lugares que se entrelazan para conformar un territorio consolidando fuertes referentes comunes. Con el sostén estatal, el algodón se constituyó en un elemento identitario esencial de la amplia trama territorial de actores vinculados entre sí a través de procesos productivos y comerciales. Colonos, braceros, comisionistas, acopiadores, desmotadores, industrializadores primarios, y proveedores de servicios, conformaron desde la década del '30 en el pasado siglo, el conjunto de actores que generaron y sustentaron esta trama y consolidaron la tradición que generó este cultivo que se practica en la zona desde hace más de 100 años.

Ahora bien, consideramos aquí que ese proceso no fue neutro, sino que estuvo asociado a la progresiva declinación de las actividades vinculadas al ciclo agroexportador argentino a principios de la década del '30 y la consecuente intensificación de orientaciones productivas tendientes a sustentar los procesos colonizadores y la gran oleada inmigratoria que confluirá en el Chaco con la creación de colonias agrícolas y agropastoriles. Los cultivos industriales duplicaron su superficie a partir de esa década y el Nordeste se destacó en el país por el "oro blanco" (algodón) y el "oro verde", (yerba mate), que junto a otros cultivos de tipo subtropical pasaron a convertirse en sus pilares productivos. 
Para captar el proceso de construcción de una territorialidad productiva - la agricultura algodonera familiar, en este caso - el análisis se centró en dos ejes: por una parte los productores y su familias como actores fundamentales que desde lo cotidiano fueron construyendo sus propias dinámicas; y por otra en el accionar del sector público del Estado (a escala provincial y nacional) que sustentó de manera directa o indirecta a estos actores y al sector algodonero mediante una consideración estatal y política de sostén diferencial.

El trabajo de campo en terreno se configuró entonces como una fuente inductiva de consulta permanente. En este sentido es preciso resaltar que la difícil tarea de obtención de testimonios de las familias agrícolas constituyó el principal desafío del trabajo. Se trató de entrevistas con respuestas parcialmente estructuradas a partir de un cuestionario general. A ello se agregó la reconstrucción de historias de vida. En función de lo expresado, la opción metodológica ha privilegiado la información cualitativa que permite aproximarse de manera más profunda y dinámica a los procesos sociales por medio de entrevistas individuales y grupales, únicas y continuadas y la observación en campo. A esto se sumó la compulsa documental de archivo en los repositorios locales públicos y privados y análisis de fuentes estadísticas y censales, publicaciones oficiales y de entidades de bien público, informes técnicos y álbumes, entre otros materiales escritos.

El área de estudio abarcó la provincia del Chaco y dentro de la misma el sector agrícola que se concentra en los departamentos del centro y sudoeste. Las escalas de análisis involucraron distintos niveles que partieron del análisis micro, con trabajo de campo en las colonias agrícolas situadas en el área (Colonia Necochea, Pampa Napenay, Bajo Hondo y poblados agrícolas) para luego examinar la situación provincial y nacional. El marco temporal general (1997-2017) consideró los acontecimientos que transcurrieron en ese lapso, sin descuidar los procesos previos.

Figura 1 - trazado aproximativo del área algodonera tradicional Chaqueña

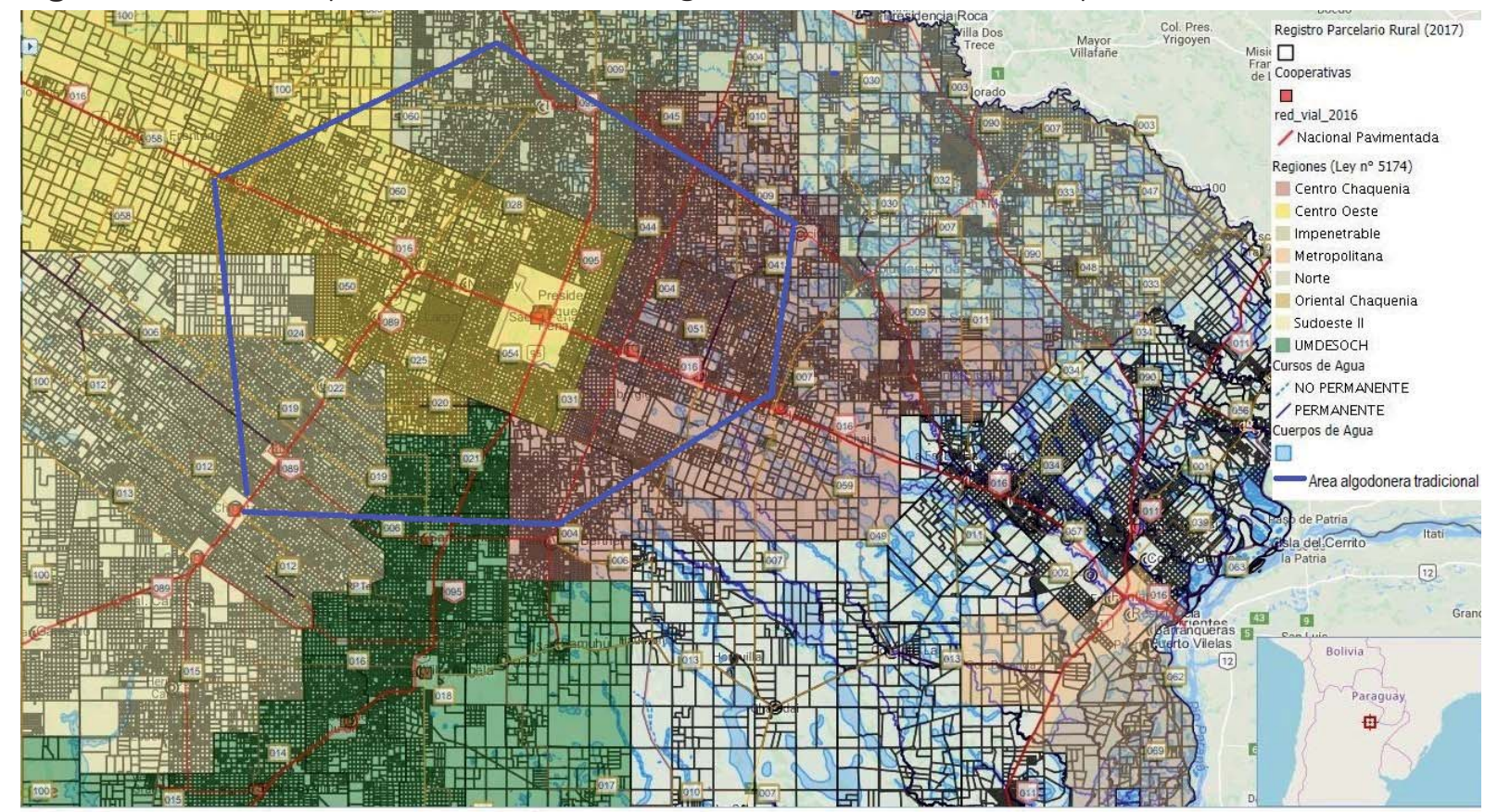

Fuente: Elaboración propia sobre base cartográfica tomada de: <http://idechaco.gob.ar/index.php?option=com_ content\&view=article\&id=748: mapa-provincia-del-chaco-con-localidades-y-parajes\&catid=31\&itemid=101> . 
El énfasis puesto en la indagación de los acontecimientos de los últimos 20 años obedece a que en ese período se intensificó el impacto de la expansión de las nuevas formas de producción y gestión de la agricultura, que generaron una desestabilización de las condiciones de inserción de la territorialidad algodonera tradicional, a pesar del sostén ejercido por la política pública. Aquí es válido referirse a estos procesos como de desanclaje o desterritorialización de la producción algodonera siguiendo a Giddens (1994 , p. 101) que define el proceso de desanclaje como "el "despegar" las relaciones sociales de sus contextos locales de interacción y su reestructuración en intervalos espacio-temporales indefinidos. Siguiendo el razonamiento, el "desanclaje" ocurriría cuando los componentes de radicación espacial son perfectamente sustituibles por otros, que no son específicos de un determinado lugar. Un ejemplo apropiado de este desanclaje lo constituyen las nuevas prácticas de la agricultura empresarial desterritorializada, asociada a agentes que se incorporan de manera especulativa y temporaria a la producción agrícola provincial. Y sumando lo que señala Herner (2009) cuando expresa que la desterritorialización implica, además, "[...] la desarticulación del referente clave de las culturas: el territorio, espacio común donde se materializan las prácticas, que marca las fronteras entre "nosotros" y los "otros" (los de "adentro" y los de "afuera")".

La dialéctica espacial que se planteó en los últimos 20 años en el área agrícola Chaqueña, involucró por un lado a una territorialidad algodonera tradicional con prácticas productivas consolidadas históricamente y por otro a una constante presión expansiva de "la nueva agricultura" asociada a eventos transgvalenzueladepompert@gmail.coménicos (soja y algodón) y definida por su alta rentabilidad dependiente de paquetes tecnológicos y escaso anclaje territorial. Y esa coexistencia espacial de modalidades de manejo productivo donde las motivaciones y los intereses eran muy disímiles generó una interacción por parte de ambos conjuntos de agentes en la que el acompañamiento estatal siempre fue coyuntural, esto es, no formó parte de una política integral de desarrollo con equidad social y sustentabilidad.

Mientras la pequeña agricultura familiar tradicional "resistió" a partir de la amenaza de pérdida de su principal sostén, que siempre fue la propiedad de la tierra, la nueva agricultura de tipo empresarial se instaló aceleradamente aprovechando la creciente demanda de comoditties para exportación, y en su "aterrizaje" temporal, elevó los costos locales de adquisición del paquete tecnológico, contribuyendo a un drástico descenso de la oferta de trabajo y a una creciente terciarización de los circuitos de provisión de insumos, de servicios de maquinaria y de compra de la producción. Los nuevos agentes oriundos - y residentes - en otras jurisdicciones de la Argentina, derivaron hacia otros ámbitos - extraprovinciales - la reinversión de las ganancias y ejercieron una demanda altamente especulativa en el mercado de alquiler de la tierra productiva, entre otros efectos.

En el devenir de estos procesos se puso de manifiesto la importancia y necesidad de una política de desarrollo rural cuya ausencia imposibilitó una evolución productiva que le asegure bienestar y progreso al productor pequeño y mediano. Como señalan Catalano y Mosse (2013) "el rol del Estado, que fue fundamental en los procesos de ocupación territorial continua siendo indispensable a la hora de garantizar un desarrollo productivo con equidad social y sostenibilidad ambiental".

Para profundizar en lo expresado hasta aquí, se examinarán a continuación los procesos de ocupación y organización económica del espacio Chaqueño que resultaron en la consolidación del "territorio algodonero", para luego analizar los principales transformaciones que afectaron al mismo y conformaron un nuevo conjunto de territorialidades cuya coexistencia plantea nuevos interrogantes a la planificación de estrategias de desarrollo rural. 


\section{EL ALGODÓN COMO LA BASE AGRÍCOLA DE LA ORGANIZACIÓN DEL TERRITORIO CHAQUEÑO EN EL PRIMER TERCIO DEL SIGLO XX}

En el Chaco, el algodón operó como un factor de atracción para la ocupación del interior del territorio con colonias agrícolas creadas entre 1921 y 1953 comprendiendo 1.029 .653 hectáreas. El poblamiento masivo asociado a la expansión del ferrocarril llevó a esta jurisdicción a registrar el crecimiento más alto del país entre 1920 y 1934, período en que la población pasó de 60.500 a 314.000 habitantes. La expansión colonizadora era acompañada por la prensa oficial y a "venir a poblar esas colonias" invitaban entre 1922 y 1939 las publicaciones de la época, como la Revista Riel y Fomento, que constantemente resaltaba las bondades de cultivar algodón en el territorio chaqueño, brindando además información específica sobre herramientas y todo lo necesario para iniciarse como algodonero en el Chaco. Calificado en 1922 por esta revista de fomento de los ferrocarriles estatales como una "región agrícola de gran porvenir" y como "un fiel exponente del progreso agrícola", la propaganda oficial era intensa y sostenida.

La prensa de la época, por medio de distintas publicaciones contribuyó mucho a la promoción del algodón: La referencia al Chaco como la jurisdicción del "oro blanco" es apreciable en los testimonios y en los registros colectivos de diarios y revistas locales desde la década del '20. Ya en 1922 señalaban que:

Algodón

Es el cultivo más importante del Chaco, y constituye en cierto modo la base de la producción agrícola. Salvo raras excepciones, todos los colonos cultivan esta malvácea, que aún en los años peores les asegura un buen rendimiento...el algodón es por excelencia el cultivo de aquella zona. (RIEL Y FOMENTO, 1922, p. 73).

El cuarto poder ha contribuido en no menor escala, con su prédica diaria al fomento de su cultivo en el país. También lo hacen, con marcado optimismo los poderes públicos de la Nación, directamente interesados en ello; los técnicos profesionales, especializados en la materia y los Ferrocarriles del Estado, de años atrás, vienen fomentando también el desarrollo de esta planta en todas sus formas posibles [...]. (RIEL Y FOMENTO, 1925a, p. 59).

Para esa fecha, la publicación convocaba en un aviso a página entera a "Braceros para la cosecha de algodón, una oportunidad de ganar un buen jornal cosechando algodón se presenta en la zona norte de los ferrocarriles del Estado" mencionando los pueblos del interior del Chaco y seguía explicando que "Con la utilidad de una cosecha se puede al año siguiente sembrar un lote fiscal y recoger entera la cosecha propia" (RIEL Y FOMENTO, 1925a, p. 1).

El oro blanco no lo recogen sino aquellos colonos que realmente trabajan bien la tierra y cuidan mejor sus plantíos. El Censo Algodonero que actualmente realizan empleados del Ministerio de Agricultura de la Nación nos va a revelar muy pronto, que la superficie sembrada con ese textil se ha duplicado; pero, este aumento en el área sembrada responderá a un igual aumento en el número de colonos dedicados a su cultivo?, o será que el colono, estimulado por tanta propaganda y por los precios siempre altos en su cotización ha duplicado el área sembrada? (RIEL Y FOMENTO, 1925a, p. 59).

El mismo ejemplar ofrecía rebajas en fletes y pasajes para colonos que quisieran ir a colonizar la zona de influencia de los ferrocarriles del Estado del norte argentino, que cruzaba el territorio chaqueño de sureste a noroeste.

"Una de esta chacras puede ser suya, el Chaco es la región de las tierras del porvenir" decía una de las múltiples propagandas de esos años (RIEL Y FOMENTO, 1926, p. 81). 
Figura 2 - Ejemplo de propaganda oficial a través de la Revista "Riel y Fomento". Órgano oficial de difusión de los Ferrocarriles del Estado Argentino

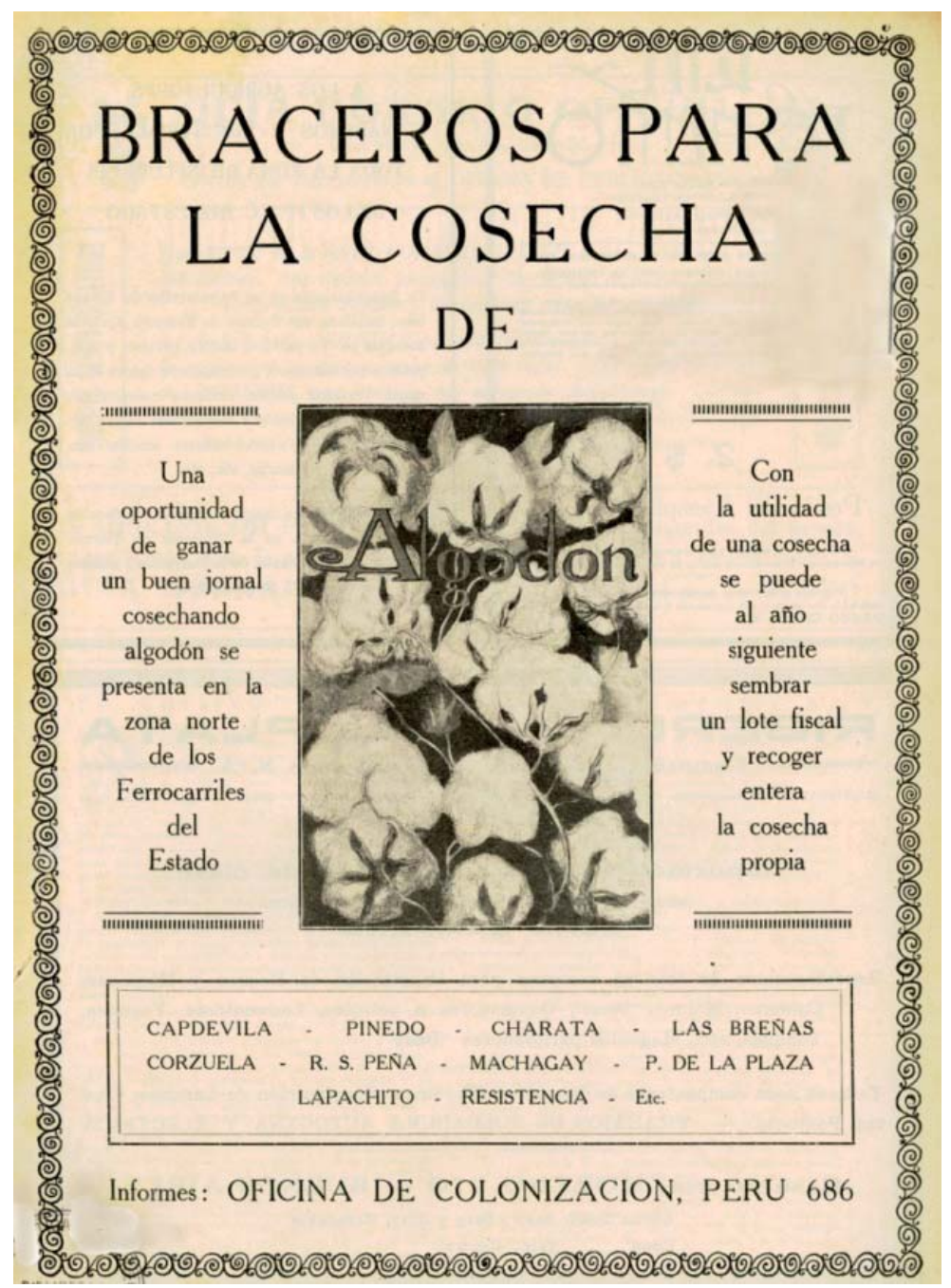

Fuente: Revista RIEL Y FOMENTO (1925a).

Simultáneamente, la publicación reclamaba la necesidad de otorgar créditos a los colonos recién instalados:

[...] las tierras del Chaco se pueblan de colonos, en su mayoría extranjeros, que están acostumbrados a que los agricultores sean ayudados en toda forma por las instituciones oficiales, especialmente los alemanes e italianos, que en su patria tienen las "Cajas Rurales" creadas con ese fin [...]. (RIEL Y FOMENTO, 1925b, p. 63).

En el mismo artículo se resaltaba el ejemplo del Banco Agrícola del Paraguay, que hacía 40 años ayudaba a los agricultores, para peticionar la creación, dentro del Banco de la Nación Argentina, la creación de una sección especializada en el sector. A escala local, la Asociación de Fomento y Defensa de los intereses del Territorio, y la Sociedad Rural del Chaco también realizaron gestiones durante la década del veinte solicitando créditos especiales para los agricultores algodoneros en el Banco de la Nación, así como la apertura de sucursales en el interior (CARLINO, 2009, p. 8).

CARLINO (2009) señala que la instalación en el territorio del "gran capital" ocurrió a principios de 1926, cuando : 
[...] se constituyó la Cámara Algodonera de Buenos Aires siendo sus miembros fundadores: Bunge y Born Cía. Ltda., Louis Dreyfus y Cía., Compañía General de Fósforos, Fábrica Argentina de Alpargatas, Bonifacio López, Valverde Lyon, B. F. Avery, Agar Cross Cía., Moring y Cía., Cía. Algodonera del Río de la Plata, Comercial Belgo-Argentina, entre otras firmas exportadoras.

La rigurosidad del clima no dejaba de ser señalada por la prensa oficial, la que advertía que: "Es muy distinto ser chacarero en la Provincia de Buenos Aires que serlo en el Chaco" (RIEL Y FOMENTO, 1926, p. 89). No obstante ello, el avance de las colonias hacia el interior y el auge del cultivo, llevó, por ejemplo, a que en abril de 1926 se realizara el Primer Congreso Algodonero Argentino en la capital del Chaco, en la ciudad de Resistencia.

En el año 1929, a instancias de la Cámara Algodonera de Buenos Aires comenzó a funcionar el Mercado Central Algodonero en la estación Buenos Aires de la Compañía General de Ferrocarriles. Esta institución difundía, a través de su revista "La Gaceta Algodonera" el estado del mercado algodonero mundial así como promovía la colonización y realizaba campañas de propaganda del algodón nacional en el exterior. Entre otros propósitos de la publicación que contribuían a consolidar sus intereses en esta actividad económica estaban los de distribuir gratuitamente la semilla y adherir y colaborar en los concursos algodoneros de las distintas. Ya en esta etapa se comenzaban a advertir las consecuencias de la conformación de un mercado oligopsónico:

[...] La caída de precios se agravó por el control del mercado algodonero del Chaco por la empresas Bunge y Born, y Dreyfus y Cía, Ltda, S.A. y otros grandes acopiadores. En 1935 funcionaban 98 desmotadoras de algodón de las cuales 40 proveían del producto a estas empresas. Las cooperativas, que en 1937 llegaban a 20, también estaban vinculadas a grandes acopiadores que proveían de crédito a las desmotadoras y comerciantes y a través de ellos a los colonos [...]. (CARLINO, 2009, p. 10).

El "oro blanco" generaba un intenso movimiento de personas y capital que confluían en el territorio Chaqueño. Al respecto, Mari (2009, p. 22) refiriéndose resalta que:

[...] las labores inherentes al cultivo (carpida) y recolección del algodón en el Chaco fueron íntegramente manuales hasta años recientes. Ello requería periódicamente la incorporación de fuertes contingentes de braceros para ser destinados a estas faenas, que, por ejemplo, para la campaña 1935-36 involucró a 129.639 trabajadores. (MINISTERIO DE AGRICULTURA, 1936, p. 88).

En suma, los intereses económicos de la época y el impulso estatal de promoción y sostén de la ocupación y organización del espacio del interior Chaqueño coadyuvaron al fortalecimiento de un territorio algodonero, identificado como tal en el contexto agrícola nacional y proveedor del mercado interno en su etapa expansiva del segundo tercio del siglo XX.

\section{LAS CARACTERÍSTICAS DE LAS FAMILIAS AGRICULTORAS ALGODONERAS}

En ese contexto de ocupación de la tierra, la pequeña propiedad caracterizó la ocupación del espacio fiscal del interior del Chaco, ya que se asignaron parcelas que promediaron entre 30 y 50 hectáreas, tamaño por entonces suficiente para explotaciones de tipo familiar. Y el algodón se constituyó en el cultivo hegemónico. En un medio natural difícil, la gran mayoría de los colonos tomó el pedazo de tierra que podía trabajar y la semilla de algodón brindada por el Estado y en ese proceso quedó establecido el perfil del sector agrícola chaqueño. Instalados en las colonias el 
cultivo de algodón pudo no sólo mantenerse sino expandirse rápidamente merced a una política de sostén ejercida por los gobiernos municipales, territorianos, y posteriormente provinciales.

Tratándose de una agricultura de secano, el monocultivo algodonero tuvo una vorágine expansiva asociada a la creciente demanda del consumo interno. Cuando éste se estancó a finales de la década del '60, la crisis consecuente llevó a una alternancia que permitió integrar nuevos cultivos anuales al conjunto productivo. No obstante ello, el algodón mantuvo, con fuertes oscilaciones, el lugar principal hasta fines de los '90. Promediando esta década, una profunda reestructuración de la agricultura, con la acelerada difusión de tecnologías transgénicas en un marco de expansión de modalidades productivas de tipo empresarial fue causando el progresivo abandono de las prácticas y costumbres de las familias agricultoras poseedoras de pequeñas explotaciones. Estos procesos de reestructuración, con la injerencia de nuevos actores y prácticas, transformaron a la agricultura en el Chaco en una actividad lucrativa altamente especulativa.

Figura 3 - Colonias agrícolas en el centro del territorio del Chaco

\section{Distribución de la tierra en Chaco y Formosa. 1990.}

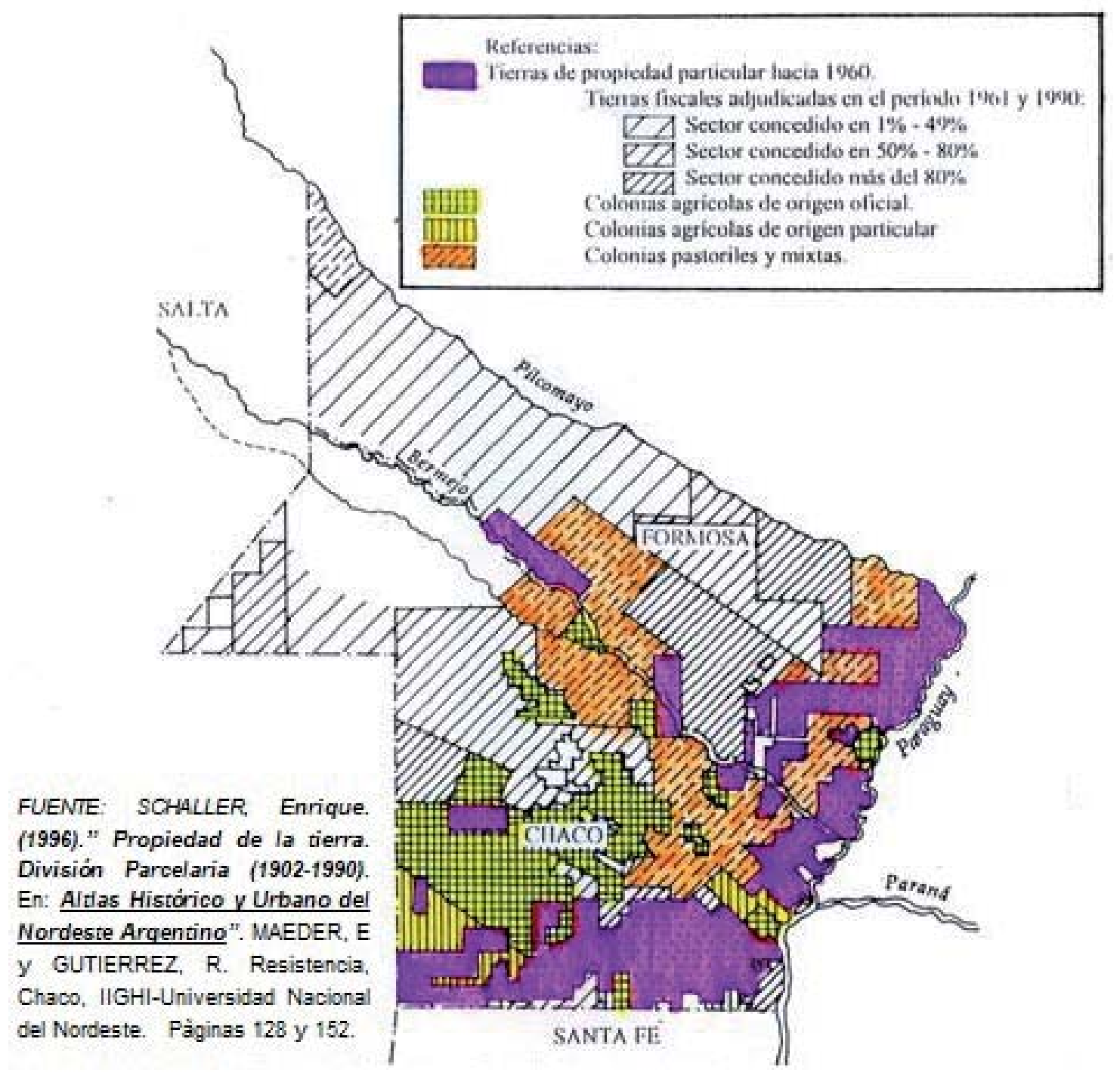




\section{LAS HABILIDADES Y PRÁCTICAS PUESTAS EN JUEGO POR LOS ALGODONEROS HISTÓRICOS PARA PERMANECER EN EL CAMPO}

Al arraigarse desde su inicio la producción entre familias, este fue el rasgo distintivo del cultivo del algodón durante gran parte del siglo XX. Considerando los principales rasgos de la agricultura familiar explicitados en el Foro Nacional de la Agricultura Familiar (2006) ${ }^{2}$, esta debe enfocarse como una "forma de vida" y "una cuestión cultural", que tiene como principal objetivo la "reproducción social de la familia en condiciones dignas". Esta definición considera que la gestión de la unidad productiva y las inversiones son realizadas por individuos que mantienen entre sí lazos familiares, la mayor parte del trabajo es aportada por sus miembros, la propiedad de los medios de producción (aunque no siempre de la tierra) pertenece a la familia y es en su interior donde se realiza la transmisión de valores, prácticas y experiencias.

La antigua trama territorial agrícola del Chaco construida secularmente por pequeñas unidades de tipo familiar surgidas de los procesos colonizadores en la primera mitad del siglo $X X$, se ha ido transformando progresivamente, no obstante lo cual sobrevive en ciertos espacios anclada en pequeñas y medianas unidades productivas que no superan las 100 hectáreas y que constituían en 2002 más del 50\% del total de explotaciones agropecuarias de la provincia ${ }^{3}$.

La suma de factores tales como, el reparto de la tierra para las familias y la especificidad de la producción, que requería la cercanía entre el cultivo la operación industrial de primera transformación (desmote), fueron factores que contribuyeron al anclaje territorial de este modo de vida en los pueblos del interior provincial. Algunas rutinas arraigadas influyeron notablemente para la persistencia de la siembra de algodón en el segundo tercio del siglo XX, como por ejemplo, la provisión de insumos para la siembra y la compra segura de la producción por parte de la Cooperativa de cada pueblo en el área algodonera Territoriana ${ }^{4}$, así como también la recurrencia en la contratación de familias de cosecheros, que volvían anualmente a trabajar en los mismos campos etc. Estas condiciones no eran fácilmente sustituibles, incluso en épocas de crisis del precio del textil o de contingencias meteorológicas que perjudicaban la cosecha.

Las acciones esporádicas tendientes a ayudar a los agricultores pueden dividirse según la extensión de las explotaciones agropecuarias. En el caso de los productores considerados minifundistas, poseedores de unidades con extensiones inferiores a las 25 hectáreas la asistencia

\footnotetext{
${ }^{2}$ Disponible en: <https://www.agroindustria.gob.ar/sitio/areas/prodear/biblioteca/_archivos//000002-Foro\%20 Nacional\%20de\%20la\%20Agricultura\%20Familiar/000001-Documento\%20de\%20Mendoza\%20-\%20Foro\%20 Nacional\%20de\%20la\%20Agricultura\%20Familiar.pdf>.

${ }^{3}$ Según los datos del Censo Nacional Agropecuario del año 2002, las tres principales provincias productoras de algodón (Chaco, Formosa y Santiago del Estero) exhiben las mismas características en su estructura agraria. Se trata de un esquema bipolar con predominio de tamaños extremos: más del $50 \%$ de las explotaciones agropecuarias con límites definidos de estas tres provincias tienen una extensión de menos de 100 hectáreas. El 30\% restante corresponde a explotaciones de 100,1 a 500 hectáreas y el 20\% restante concentra las explotaciones de más de 500,1 hectáreas. Por su parte, la mitad de las explotaciones agropecuarias de estas provincias tienen menos de 100 hectáreas de extensión y ocupan sólo un 5\% de la superficie agropecuaria, las explotaciones de 100,1 a 500 hectáreas ocupan un $15 \%$ y las de más de 500,1 hectáreas abarcan el $80 \%$ de la superficie agropecuaria de cada jurisdicción.

${ }^{4}$ La época "Territoriana" refiere al período abarcado por la primera mitad del siglo XX, en el cual el Chaco fue un Territorio Nacional dependiente del Gobierno Central. Los Territorios Nacionales creados por la ley 1532 fueron: La Pampa, Neuquén, Río Negro, Chubut, Santa Cruz, Tierra del Fuego, Misiones, Formosa, y Chaco. Uno de los Territorios surgidos bajo esta nueva organización fue el "Chaco", aunque con límites algo más acotados, ya que la anterior Gobernación creada con cierta premura en 1872 luego de finalizada la guerra con el Paraguay, fue dividida en dos unidades (Chaco y Formosa), con sus respectivas autoridades.
} 
reiterada por parte de programas de los gobiernos nacionales, provinciales y municipales ha consistido en la provisión de gasoil, servicios de labranza, semilla para siembra e insecticidas, que han permitido a este segmento continuar destinando una porción de sus predios al cultivo de algodón.

Los productores familiares con explotaciones de 25 a 100 hectáreas han podido continuar sembrando mediante el intercambio de insumos en circuitos informales. Como el acceso a préstamos no es general, los canjes que les permiten seguir produciendo se traducen en anticipos y préstamos de comerciantes y acopiadores locales y a veces la cesión temporal a proveedores de insumos, de un lote del campo o de un porcentaje de lo obtenido en la cosecha. Estos circuitos "alternativos" parten de la base de un canje desigual e implican tanto esfuerzos, como perjuicios adicionales, por ejemplo un descenso de los rindes, ya que al no tener acceso a las últimas semillas híbridas que ofrece el mercado para mejorar el rendimiento por hectárea, utilizan un semillero propio que es el resultado del desmote del algodón que le vendieron a los acopiadores. Estas semillas adquiridas a los acopiadores no siempre poseen un buen rinde, ya que es producto de semillas híbridas de primera calidad que han ido perdiendo efectividad con las siembras sucesivas. Los agroquímicos son adquiridos de modo fraccionado a otros productores más grandes que tienen acceso al mercado formal o a los acopiadores, ya que estos productos se venden en bidones cerrados en las grandes empresas de la zona. El pago por los servicios de maquinaria o los insumos provistos por los productores más grandes se acuerda por medio de la cesión temporal al proveedor de un lote del campo o de un porcentaje de lo obtenido en la cosecha.

Los agricultores negocian el precio de la tonelada de algodón con acopiadores privados que ofrecen recoger la producción en la explotación, descontando al productor los costos de carga y flete. En estas transacciones, la urgencia juega un papel negativo que muchas veces induce al agricultor a aceptar precios poco convenientes.

Las opciones para obtener otros ingresos una vez vendido el algodón, admiten un reducido conjunto de alternativas: alquilar una parte del campo, sembrar hortalizas o criar cerdos o pollos para vender en el pueblo. Los más jovenes de la familia se ofrecen como operarios de maquinaria para la actividad sojera en el sudoeste, o para el desmonte en el noroeste, migrando temporariamente. El consumo familiar se reduce a insumos indispensables y "se aguanta" hasta la próxima cosecha. Este ciclo de pervivencia se matiza con los intercambios vecinales y algunas opciones circunstanciales de "changas" y trueques. Todo el esquema se apoya en la posesión

de la tierra. Aunque se alquile una parte del campo, el productor siempre se reserva una porción para autoconsumo y venta ocasional en el pueblo cercano, o canje vecinal.

La pervivencia, en tanto continuidad de los pequeños y medianos agricultores familiares se apoya en un tipo de resistencia poco evidente, sustentada por alianzas interpersonales tácitas que no forman necesariamente parte de expresiones colectivas organizadas. El sostén principal de identidades asociadas a las prácticas productivas tradicionales han sido las redes primarias, de parentesco, amistad y proximidad que constituyeron un soporte importante en el proceso de reorganización y resistencia a la presión de la nueva jerarquía de territorialidades.

La reproducción de prácticas se justifica discursivamente en la tradición, en el conocimiento del propio campo (su suelo, las variaciones meteorológicas, las plagas, etc) y lo que el productor y su familia consideran como la decisión "más conveniente" cada año. Esto se enmarca en un ámbito donde los cultivos anuales de secano se circunscriben a seis opciones, que por orden de importancia son: algodón, girasol, soja, maíz, sorgo y trigo. La horticultura es vista como opción 
para la alimentación o la venta muy excepcional.

El discurso identitario se aferra a la tradición y señala repetidamente que se siembra algodón "porque somos algodoneros desde hace años. En mifamilia hace 60 años que somos algodoneros". Variando el número de años, este discurso es reiterativo e indica un anclaje identitario que no debe ser visto como un problema, sino como un recurso para una reconversión digna, que le posibilite al agricultor vivir "de su sudor" y poder dejarle la tierra a sus hijos. La producción algodonera tradicional, como "lógica de la resistencia" no se opone a las nuevas tendencias difundidas en los últimos diez años, sino que aspira a una pervivencia en un planteo de reproducción de prácticas con un fuerte componente identitario históricamente asociado al cultivo del algodón.

\section{EL SOSTÉN DE LA TERRITORIALIDAD ALGODONERA POR PARTE DE LA POLÍTICA PÚBLICA. LAS INICIATIVAS POLÍTICAS PARA EL SOSTÉN DE LOS SEGMENTOS MÁS VULNERABLES}

El sostén estatal posibilitó en gran medida la supervivencia de un amplio espectro agentes productivos con un muy desigual poder de negociación, que pudo mantenerse merced a una política de sostén indirecto, ejercida por los gobiernos municipales y provinciales que consideraron al cultivo de algodón como el distintivo territorial generador de trabajo.

Las medidas para fomentarlo a escala nacional y provincial llevan más de 90 años, considerando como punto de partida al Primer Congreso Algodonero Argentino, siguiendo a Larramendy y Pellegrino (2005 , p. 206) que se realizara en 1926 en la ciudad de Resistencia. Se trata en general de medidas aisladas e instrumentadas según las coyunturas que no consolidaron una estrategia integral de desarrollo de toda la cadena de valor asociada al textil, posibilitando la pervivencia pero no el progreso integral de los agricultores.

El examen de las acciones desarrolladas a nivel provincial y nacional para sostener a la producción algodonera admite dos lecturas. Por una parte revela la elogiable intención de promover estrategias compensatorias de enorme valor político en términos del corto plazo, a partir del reconocimiento de problemáticas que no habían sido hasta el momento suficientemente explicitadas ni atendidas de modo sostenido a nivel de decisiones estatales. Por otra parte, en las políticas tanto propuestas como en ejecución - subyace una división que ha sido denominada en los análisis más recientes de estrategias de política para el desarrollo rural, como la "dualidad perversa" entre las políticas para los "viables" y las otras, para los "inviables" ${ }^{5}$. La intervención del poder político institucional para subsanar temporalmente procesos de subordinación estructural entre productores de bajo poder e intermediarios, no es sino la confirmación - más implícita que explícita - de que la ayuda es entendida más como una estrategia compensatoria destinada a paliar coyunturalmente las desigualdades, que a generar posibilidades reales de inserción y desarrollo económico de los segmentos más desfavorecidos. No obstante este sesgo, es apreciable la intención de mejorar la calidad del gasto público destinado a las estrategias de política para el desarrollo rural.

\subsection{Algunas iniciativas de sostén y promoción del algodón en el Chaco}

¿Qué instrumentos utilizó la gestión pública provincial y nacional para contribuir al sostén de la agricultura familiar en el sector algodonero Chaqueño en los últimos 20 años?. La diversidad

\footnotetext{
${ }^{5}$ Para ampliar ver: Echeverri Perico (2009).
} 
de mecanismos de sostén que han tratado de implementar desde la política pública es uno de los rasgos distintivos de la evolución del algodón en la Argentina desde hace más de 5 décadas.

Al respecto cabe citar la síntesis que Larramendy y Pellegrino (2004, p. 206) efectúan hasta 2004 y denominan como "Momentos culminantes de la evolución de la política del algodón hasta 2004", donde consideran una extensa lista de acciones significativas en el marco de la política algodonera, partiendo de 1923, con la creación de la Estación Experimental para el cultivo del algodón en la localidad de Presidencia Roque Sáenz Peña, hasta el funcionamiento en 2004 de la Mesa Algodonera Nacional. Como ejemplo, podemos resaltar las siguientes:

- 1935: Junta Nacional del Algodón (Decreto 61.640 PEN).

- 1943: Creación de la Dirección del Algodón (Decreto 15.317 PEN).

- 1958: Creación de la Junta Nacional del Algodón (Ley 14.770).

- 1970: Creación del Fondo Compensador Algodonero de la Provincia del Chaco (Ley 1007).

- 1982: Creación de la Comisión Nacional de Política Algodonera Integral en la Provincia del Chaco.

- 1989: Creación del Consejo Algodonero Nacional.

- 2000: PROINTAL (Proyecto Integral Algodonero) y Foro Algodonero Regional

- 2004: Funcionamiento de la Mesa Algodonera Nacional.

A esta secuencia es posible agregar las medidas tomadas fundamentalmente a escala nacional en los últimos 10 años, apuntando al acompañamiento de la producción algodonera, mediante acciones tales como:

- 2006: Ley 26.060 de Fomento de la Producción Algodonera y de creación de un Fondo Compensatorio.

- 2008: Subsidios para estrato de 10 y 100 hectáreas, recibirán entre 250 y 300 pesos por hectárea de siembra

- 2008: Creación del PROCALGODON. Programa de Asistencia para el Mejoramiento de la Calidad de la Fibra de Algodón creado por resolución 537/2008 de la ex Secretaria de Agricultura, Ganadería, Pesca y Alimentos, tiene como finalidad mejorar el proceso productivo y tecnológico del algodón, desde su inicio hasta la salida de los fardos de fibra de algodón a los mercados nacional e internacional, contribuyendo así a valorizar el producto en función de la calidad y a elevar la competitividad del sector.

- 2010: Ley de creación del Régimen de Consorcios Productivos de Servicios Rurales, del Chaco. Por ley provincial n. 6547 se crearon en 2008 los Consorcios Productivos de Servicios Rurales (en adelante CPSR), concebidos como entidades de bien público de servicios a la comunidad, sin fines de lucro, integrados por vecinos de una zona determinada, con el objeto de aunar esfuerzos y aportes económicos de distinta naturaleza para la ejecución de trabajos en predios rurales tendientes a posibilitar el laboreo de tierras para una más óptima producción rural.

- 2011: Ley n. 6.837- Crea la Comisión Provincial de Sanidad Vegetal (COPROSAVE).

- 2013: Programa de Desarrollo Rural y Agricultura Familiar (PRODAF).

En términos generales las acciones de sostén de la producción algodonera involucraron créditos a corto plazo en el marco de la Ley 26060, aportes no reintegrables, aportes directos de gasoil y agroquímicos (para productores minifundistas y la creación de nuevos programas, como los mencionados más arriba. 
En julio de 2016 los propósitos de la política pública apuntaban a mejorar las intenciones de siembra y expresar el compromiso con el sector y sobre pequeños y mediados productores, siguiendo el discurso oficial que expresaba "Queremos que el algodón sea un cultivo rentable en el Chaco porque ya logramos desarrollar una cadena algodonera con todo lo que es la producción primaria, el hilado, la fabricación de tela y la confección textil” ${ }^{(6)}$ y proponía un nuevo programa algodonero para incentivar la siembra de buena calidad, apuntando a la fiscalización de la semilla y los circuitos de comercialización.

Ante la inminencia del inicio de la campaña 2016-17, en julio de 2016 el representante del poder ejecutivo de la provincia del Chaco ratificó el objetivo de potenciar el algodón como "identidad industrial" del Chaco. Y apoyar a pequeños productores e incentivar el desarrollo de toda la cadena algodonera. No obstante ello, el panorama se presentaba incierto en 2017. Al respecto señala RUIZ, en un diario Chaqueño a principios de año (RUIZ, 2017) "Es evidente que la industria, el principal consumidor de fibra argentina, debería hacer mucho para incentivar la producción".

\section{CONSIDERACIONES FINALES}

La construcción del territorio algodonero chaqueño es un ejemplo de especialización productiva y organización socio-territorial guiada por la política pública que surgió a la vera del ferrocarril, se ancló en las colonias estatales y se consolidó con la afluencia de colonos en el interior provincial.

Esa identidad productiva fue acompañada en su anclaje por la prensa oficial y por la política pública pudiendo afirmarse que el algodón fue y continúa siendo un instrumento para los discursos y las acciones institucionales enmarcadas en la defensa de los intereses del Chaco. El algodón ha sido uno de los soportes fundamentales, quizás el más importante en la construcción de una trama territorial que se gestó con su difusión, arraigo y evolución y la producción algodonera ha sido un rubro que representó durante todo el siglo XX un importante porcentaje del producto bruto provincial en las primeras fases de transformación.

El examen de la innumerable lista de acciones tendientes a favorecer, sostener, dinamizar, proteger y o promover el cultivo del algodón en el Chaco, revela la innegable intención de sostener a los agentes más vulnerables involucrados en esa producción.

Esta intención ha sido una constante en que ha garantizado la continuidad de una producción atomizada que pervive mediante un tipo de resistencia poco evidente, apoyada en alianzas interpersonales tácitas que no formaron necesariamente parte de expresiones colectivas organizadas. El sostén principal de identidades asociadas a las prácticas productivas tradicionales han sido las redes primarias, de parentesco, amistad y proximidad que constituyeron un soporte importante en el proceso de reorganización y resistencia a la presión de la nueva jerarquía de territorialidades.

La ausencia creciente del sector cooperativo como intermediario de los segmentos más vulnerables y la intermediación especulativa no ha hecho sino dejar en manos del Estado la política de sostén. Este sostén consigue en cada cosecha mantener el sistema productivo pero no necesariamente a favor del creciente mejoramiento de la calidad de vida de sus protagonistas históricos, como lo fueron las familias algodoneras.

${ }^{6}$ Disponible en: <http://www.chaco.gov.ar/noticia/41436/peppo-ratifico-el-objetivo-de-potenciar-el-algodon-comoidentidad-industrial-del-chaco>. 
Las políticas de sostén se convierten entonces en un instrumento que termina beneficiando a un mercado oligopsónico sin conseguir la meta final de posibilitar al productor pequeño y mediano con un crecimiento económico que le asegure bienestar y progreso. El sostén también puede tener un efecto indeseado de favorecer a los intereses especulativos y a la proliferación de intermediarios. Justamente por ello creemos necesario expresar que el esfuerzo de todas las políticas de apoyo y sostén, si no se vuelve integrado, se transforma en una ventaja servida en bandeja para el oportunismo del mercado.

La política pública no puede soslayar la consideración de los distintos actores que intervienen en la actividad agrícola regional. Esa atención debe apuntar a generar posibilidades de un mejoramiento de las condiciones de vida en los territorios, independientemente de los intereses económicos del momento, es decir observando más allá del aumento de la productividad en determinadas cadenas de valor. Priorizar un conjunto de prácticas y tecnologías (de insumos y de procesos) por sobre los habitantes de un territorio es una lógica perversa que se alimenta de un Estado pasivo ante la "imposición" de la "modernidad" por sobre las construcciones productivas territoriales.

Por tanto, un objetivo insoslayable de la política pública debe ser el de garantizar el desarrollo productivo con equidad social y sostenibilidad ambiental. Aplicado al caso del algodón, se trata de posibilitar al conjunto de actores de la trama productiva una permanencia en el territorio con políticas públicas que atiendan sus demandas reales, valoricen sus conocimientos del territorio y les posibiliten una inserción sustentable en las nuevas tecnologías productivas.

\section{REFERENCIAS}

APARICIO, Susana. Trabajos y trabajadores en el sector agropecuario de la Argentina. En: GIARRACA, Norma; TEUBAL, Miguel (Coord.). El campo argentino en la encrucijada: estrategias y resistencia sociales, ecos en la ciudad. Buenos Aires: Alianza Editorial, 2005

CARLINO, Alicia. Los orígenes de la industria algodonera en el Territorio Nacional del Chaco. Instalación del desmotado y las aceiterías. H -industri@ - Revista de historia de la industria argentina y latinoamericana, año 3, n. 5, segundo semestre de 2009. Disponible en: <file:///C:/Users/pbc/Downloads/Dialnet-LosOri genesDeLaIndustriaAlgodoneraEnElTerritorioNa-5009911.pdf>.

CATALANO, José; MOSSE, Luis. Agricultura familiar y el rol del Estado: organizarse para crecer, desarrollarse para transformar la realidad. Voces del Fénix, Buenos Aires, n. 28, set. 2013. Disponible en: <http://www. vocesenelfenix.com/content/agricultura-familiar-y-el-rol-del-estado-organizarse-para-crecer-desarrollarsepara-transfor>.

ECHEVERRI PERICO, Rafael. Identidad y territorio en Brasil. Brasília: Instituto Interamericano de Agricultura (IICA); Secretaría de Desarrollo Territorial del Ministerio de Desarrollo Agrario de Brasil, 2009. Disponible en: <http://www.proterritorios.net/catalogo/tags.php?num=1\&tag=EXT>.

FORO NACIONAL DE LA AGRICULTURA FAMILIAR, 3-5 de mayo de 2006. Nota de presentacion y documento elaborado por las organizaciones representativas del sector productor agropecuario familiar. Mendoza, Argentina. Disponible en: <https://www.agroindustria.gob.ar/sitio/areas/prodear/biblioteca/_ archivos//000002-Foro\%20Nacional\%20de\%20la\%20Agricultura\%2OFamiliar/000001-Documento\%20 de\%20Mendoza\%20-\%20Foro\%20Nacional\%20de\%20la\%20Agricultura\%20Familiar.pdf>.

GIDDENS, A. Consecuencias de la modernidad. Madrid: Alianza, 1994.

HERNER María Teresa. Territorio, desterritorialización y reterritorialización: un abordaje teórico desde la perspectiva de Deleuze y Guattari. Huellas, La Pampa, n. 13, 2009.

LARRAMENDY, Juan Carlos; PELLEGRINO, Luis Alberto. El algodón: ¿una oportunidad perdida? La Plata: Ediciones Al Margen, 2005. 
MARI, Oscar Ernesto. La transición entre dos ciclos y sus efectos sociales en un territorio argentino. Conflictos de convivencia en el Chaco ante una nueva etapa colonizadora (1920-1940). Revista Geografica Norte Grande, Santiago de Chile, n. 42 , p. 21-40, 2009. Disponible en: <http://dx.doi.org/10.4067/ S0718-34022009000100002>.

PALACIO, Jorge; JIMENEZ OCAMPO, Enrique; CORREA DE ANDREIS, Alfredo; ROSA DÍAZ, Margarita. Desplazamiento interno forzado: restablecimiento urbano e identidad social. Universidad del Norte: Publisher, 2009.

RIEL Y FOMENTO. Buenos Aires: Republica Argentina; Organo Oficial De Los FF.CC.Del Estado, n. 56, 1926. Buenos Aires: Republica Argentina; Organo Oficial De Los FF.CC.Del Estado, n. 35, 1925a. Buenos Aires: Republica Argentina; Organo Oficial De Los FF.CC.Del Estado, n. 33, 1925b. Buenos Aires: Republica Argentina; Organo Oficial De Los FF.CC.Del Estado, n. 4, 1922.

RUIZ; Hipólito. Con un chaco en crisis, Santiago del Estero subió al podio del algodón. Diario Norte, 22 de febrero de 2017. Disponible en: <http://www.diarionorte.com/article/148720>.

\section{FUENTES ORALES Y ENTREVISTAS}

Entrevistas a Miguel Angel Fernández, director del Diario Norte, en mayo de 2014, oct./2016 y mayo/2017. Entrevista a Juan Miguel Kisiel, Gerente de la Cooperativa Agrícola Presidencia Roque Sáenz Peña Limitada. Sargento Cabral 246. Sáenz Peña. Chaco, 10 sep./2010.

Entrevista a Osvaldo Chiaramonte, Gerente de la Secretaría de Desarrollo Rural del Chaco, en jul./2010. Entrevistas a Gerente de UCAL, (Unión de Cooperativas Agrícolas Algodoneras), Sáenz Peña, Chaco, 26 sep./2012.

Entrevistas a Aldo Wuthrich, Director del INTA Sáenz Peña, 2012, Gerente de UCAL Sánez Peña, Roberto Cogno, Gerente Administrativo de Coop. Agropecuaria La Unión_y a Gabriel Chirnicinero, Director de Algodón de la Subsecretaria de Agricultura, 2012.

Entrevistas a Juana Vukich, productora algodonera en 2006 y 2009.

Entrevistas en profundidad con respuestas abiertas a los productores: Vicente V., Juan L., Pablo D., Kurt R., Daniel D., Juan C.y Pablo C. en forma reiterada en los meses de junio, julio, diciembre de 2007; febrero, julio y noviembre de 2008; julio y septiembre de 2010; julio de 2011 y febrero de 2012. Entrevistas a Luis M. y Pedro M en agosto, octubre y febrero de 2014, 2015 y 2016. En todos los casos, los productores solicitaron la no inclusión de sus apellidos.

\section{Sobre la autora:}

Cristina Ofelia Valenzuela: Investigadora Principal en la Carrera del Investigador Científico del CONICET. Doctora, Licenciada y Profesora en Geografía. Especializada en temas de desarrollo regional y local y problemática de las economías regionales Argentinas. Ha dirigido y dirige proyectos de investigación aprobados por CONICET y la ANPCyT. E-mail: valenzueladepompert@gmail. 
